\title{
Understanding the Radial Force of Stroke Thrombectomy Devices to Minimize Vessel Wall Injury: Mechanical Bench Testing of the Radial Force Generated by a Novel Braided Thrombectomy Assist Device Compared to Laser-Cut Stent Retrievers in Simulated MCA Vessel Diameters
}

\author{
Jeffrey M. Katz ${ }^{a} \quad$ Abdullah M. Hakoun ${ }^{a} \quad$ Amir R. Dehdashti ${ }^{b} \quad$ Alex B. Cheblc \\ Vikram Janardhan ${ }^{d}$ Vallabh Janardhan ${ }^{d}$ \\ aDepartment of Neurology, North Shore University Hospital, Manhasset, NY, USA; \\ ${ }^{b}$ Department of Neurosurgery, North Shore University Hospital, Manhasset, NY, USA; \\ ${ }^{c}$ Harris Stroke and Neurovascular Center, Henry Ford Health System, Detroit, MI, USA; \\ dDivision of Stroke Devices Research, Insera Therapeutics, Inc., Dallas, TX, USA
}

\section{Keywords}

Acute ischemic stroke - Large vessel occlusion - Stent retrievers - Thrombectomy assist devices $\cdot$ Radial force $\cdot$ Vessel wall injury

\begin{abstract}
Background: Recent reports have raised various concerns about the risk of vessel wall injury while withdrawing current laser-cut stent retrievers during active strut apposition to the vessel walls. The development of braided thrombectomy assist devices in conjunction with aspiration systems may be gentler on the fragile brain vessels and more optimized with regard to the radial force (RF) for vessel diameters of proximal (M1) and distal (M2) large vessel occlusions (LVOs). Methods: Mechanical bench testing of the RF was performed using a radial compression station mounted on a tensile testing machine. The total RF in newtons $(\mathrm{N})$ generated in vessels with diameters ranging from 2.25 to $3 \mathrm{~mm}$ as seen in proximal LVOs ( M1), and in vessel diameters ranging from 1.5 to $2.24 \mathrm{~mm}$ as seen in distal LVOs ( M2), was measured. The outer diameter of each stent was recorded, and an RF $\leq 1 \mathrm{~N}$ was grouped as "low," while an RF $>1 \mathrm{~N}$ was grouped as "high" for this analysis. Results: The total RFs of all laser-cut stent retrievers were all higher in the simulated $M 2$ vessels $(>1 N)$ than in the $M 1$ vessels $(<1 N)$, whereas the total RFs of the braided thrombectomy assist devices were uniformly low in both
\end{abstract}


the simulated M1 and the simulated M2 vessels. Conclusions: Novel braided thrombectomy assist devices in conjunction with aspiration systems have lower RFs than existing laser-cut stent retrievers in M1 and M2 vessel diameters. Further in vivo studies are needed to delineate the impact of lowering the RF on vessel wall integrity.

(c) 2019 S. Karger AG, Basel

\section{Introduction}

Cerebrovascular disease is one of the most common causes of morbidity and mortality, with stroke being the second leading cause of death worldwide [1]. The gold standard initial management of ischemic stroke remains intravenous tissue plasminogen activator (IV tPA), administered within $4.5 \mathrm{~h}$ from symptom onset, due to its generalizable usability across multiple ischemic stroke subtypes and its broad availability [2]. However, tPA alone when used for large vessel occlusions (LVOs) has a success rate of $<20 \%$ [3], which has been attributed to its limited action in the setting of extensive clot burden and the slow temporal dynamics of chemical thrombolysis [4]. In instances where medical management fails, a combined approach with IV tPA, when indicated, and endovascular stroke thrombectomy has shown high rates of recanalization success (TICI score $2 \mathrm{~b}$ or 3 ), achieving 90-day functional independence in $46 \%$ of cases when performed within $6-8 \mathrm{~h}$ after symptom onset [5]. Similar rates of successful functional outcome are achievable even up to $24 \mathrm{~h}$ from last known well in patients selected for endovascular treatment based on CT perfusion criteria [6,7].

These clinical success rates were attained as a result of the continuous evolution of endovascular thrombectomy devices and techniques over the past two decades. However, further enhancements are necessary, as still only about half of the patients achieve the desired clinical outcome. The Mechanical Embolus Removal in Cerebral Ischemia (MERCI) retriever (Concentric Medical, Mountain View, CA, USA) was the first device designed for clot removal, and while a breakthrough in its time, it had limited rates of technical and clinical success [8]. First-generation stent retrievers such as the Trevo (Stryker Neurovascular, Fremont, CA, USA) and the Solitaire FR Revascularization Device (Medtronic - Neurovascular, Irvine, CA, USA) were developed next. More recently, there has been growing evidence in favor of aspiration systems for stroke thrombectomy $[9,10]$, and there is a shifting trend $[11,12]$ towards use of aspiration systems as first-line therapy (surveys show this to range from 39.7\% [11] to $41.12 \%$ [12]) and towards retrievable stents being used in combination with aspiration systems (surveys show this to range from 28.2\% [11] to 32.4\% [12]) with lesional aspiration, such as thrombectomy assist devices [13]. High technical success rates and ease of use of these endovascular stroke devices facilitated the mass market growth of stroke intervention in the first half of this decade, culminating in the publication of multiple randomized controlled clinical trials, beginning in 2015, proving the clinical benefit of endovascular stroke therapy $[9,10,13,14]$.

Despite the significant differences in outcome versus medical therapy alone, discrepancies between relatively high revascularization rates and their correlation with clinical outcomes and complications remain [5], and although this could be due to multiple reasons, further innovation in stroke thrombectomy devices may help. Given that retrievable stents are being used in combination with aspiration systems $[11,12]$, the question arises as to whether we really require such high-radial-force (RF) retrievable stents that can damage the vessel wall, or whether we need retrievable stents that are gentler on the vessel walls and that can act as endoluminal scaffolds for a clot, for use in conjunction with aspiration.

The continuous modification and optimization of aspiration systems for use in first-line therapy or combination therapy with retrievable stents or thrombectomy assist devices is the 
Fig. 1. a RJU124 Compression Station mounted on a tensile testing machine (TTR2 Machine Base; Blockwise Engineering, Tempe, AZ, USA). b Schematic representation of the radial force of a braided thrombectomy assist device (SHELTER; image on the right) compared to the radial forces of standard laser-cut stent retrievers.

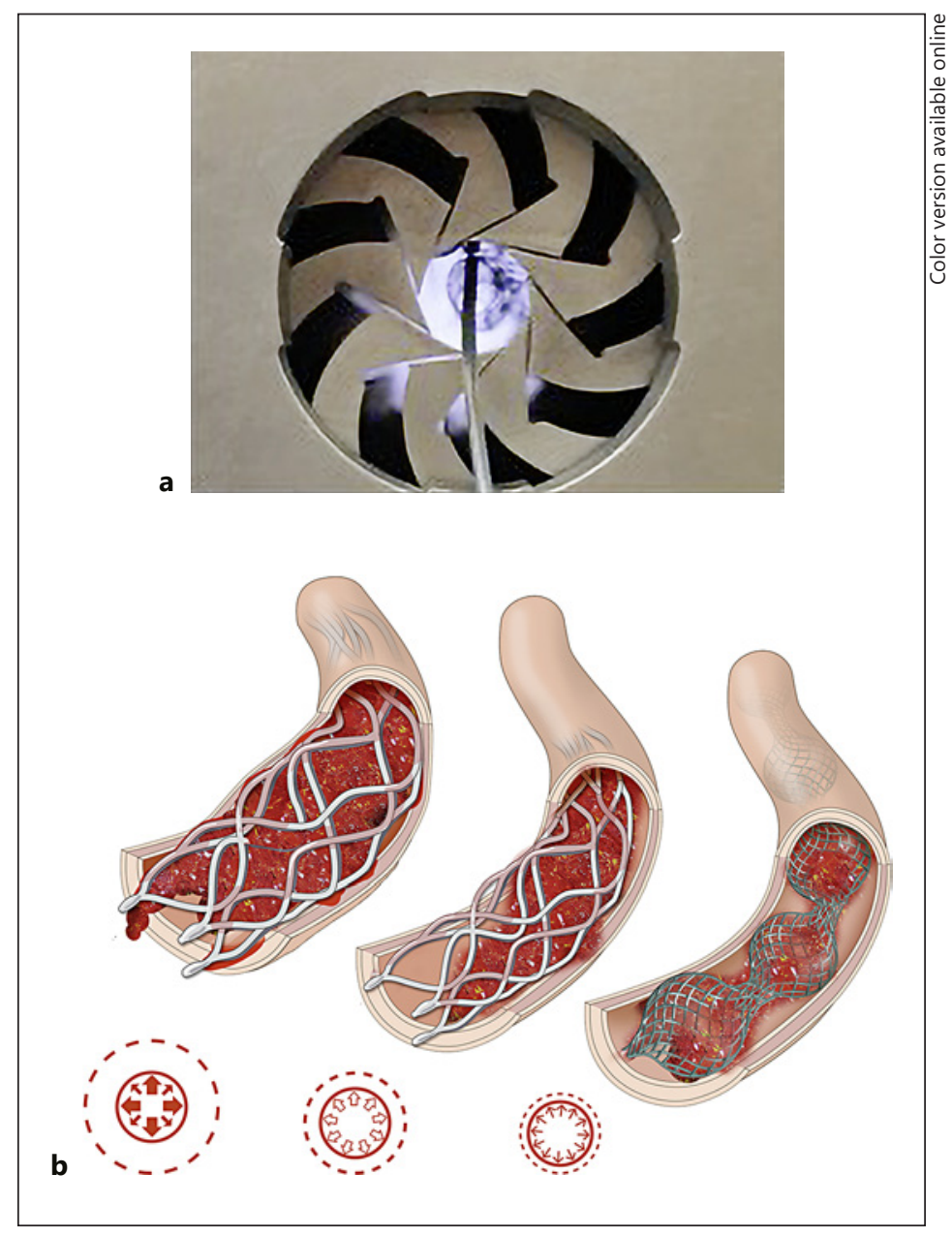

logical next step to improve these outcomes. We tested the RF of a novel braided thrombectomy assist device $\left(\right.$ SHELTER $\left.^{\circledR}\right)$ for use in conjunction with aspiration systems (CLEAR ${ }^{\mathrm{TM}}$ Aspiration System; Insera Therapeutics, Inc., Dallas, TX, USA), using a radial compression station mounted on a tensile testing machine, and compared it with the RF of existing commercially available laser-cut stent retrievers in simulated middle cerebral artery vessel diameters. The analysis and possible benefits of this original design in the future of endovascular thrombectomy assist devices will be discussed.

\section{Materials and Methods}

Mechanical bench testing of RFs generated by stent retrievers and thrombectomy assist devices was performed using a radial compression station (Fig. 1; RJU124 Compression Station) mounted on a tensile testing machine (TTR2 Machine Base) with RF testing software (Blockwise Engineering, Tempe, AZ, USA). Standard calibrations were performed prior to the start of RF testing. The temperature in the compression station was verified to be $37 \pm 2{ }^{\circ} \mathrm{C}$ using a calibrated FLUKE $1551 \mathrm{~A} \mathrm{Ex} \mathrm{Stik} \mathrm{Thermometer.} \mathrm{The} \mathrm{RF} \mathrm{measurement}$ was calibrated using a 20-lbf, type II, ASTM class 6 weight. The diameter was calibrated with an 8-mm NO-GO Class Z gauge pin $(-0.0025 \mathrm{~mm}$ tolerance). The calibration data pertaining to the tests performed included a diameter offset of $13.324 \mathrm{~mm}$, a fixture constant of $0.7376 \mathrm{~mm}$, a force offset of $-5.85 \mathrm{~N}$, a force gain of $136.76 \mathrm{~N} /(\mathrm{mv} / \mathrm{V})$, and a screw correction factor of 0.9985 . 
Table 1. RF measurements for all stent retrievers and thrombectomy assist devices tested

\begin{tabular}{|c|c|c|c|c|c|c|c|c|c|c|}
\hline \multirow[t]{2}{*}{ Device } & \multirow{2}{*}{$\begin{array}{l}\text { Distal OD } \\
\text { of device, } \\
\text { mm }\end{array}$} & \multicolumn{9}{|c|}{ MCA vessel diameters (range $1.5-3 \mathrm{~mm}$ ) } \\
\hline & & $\begin{array}{l}\mathrm{RF} \text { at } \\
3 \mathrm{~mm} \\
\text { (low or high) }\end{array}$ & $\begin{array}{l}\mathrm{RF} \text { at } \\
3 \mathrm{~mm}\end{array}$ & $\begin{array}{l}\mathrm{RF} \text { at } \\
2.75 \mathrm{~mm}\end{array}$ & $\begin{array}{l}\mathrm{RF} \text { at } \\
2.5 \mathrm{~mm}\end{array}$ & $\begin{array}{l}\mathrm{RF} \text { at } \\
2.25 \mathrm{~mm}\end{array}$ & $\begin{array}{l}\mathrm{RF} \text { at } \\
2 \mathrm{~mm}\end{array}$ & $\begin{array}{l}\mathrm{RF} \text { at } \\
1.75 \mathrm{~mm}\end{array}$ & $\begin{array}{l}\mathrm{RF} \text { at } \\
1.5 \mathrm{~mm}\end{array}$ & $\begin{array}{l}\mathrm{RF} \text { at } \\
1.5 \mathrm{~mm} \\
\text { (low or high) }\end{array}$ \\
\hline SHELTER $^{\circledR}$ Retriever & 6.0 & Low & $0.35 \mathrm{~N}$ & $0.47 \mathrm{~N}$ & $0.49 \mathrm{~N}$ & $0.62 \mathrm{~N}$ & $0.70 \mathrm{~N}$ & $0.88 \mathrm{~N}$ & $0.94 \mathrm{~N}$ & Low \\
\hline Solitaire Platinum & 6.0 & Low & $0.74 \mathrm{~N}$ & $0.84 \mathrm{~N}$ & $0.85 \mathrm{~N}$ & $1.01 \mathrm{~N}$ & $1.12 \mathrm{~N}$ & $1.36 \mathrm{~N}$ & $1.41 \mathrm{~N}$ & High \\
\hline Trevo ProVue & 4.0 & Low & $0.66 \mathrm{~N}$ & $0.83 \mathrm{~N}$ & $0.90 \mathrm{~N}$ & $1.10 \mathrm{~N}$ & $1.26 \mathrm{~N}$ & $1.53 \mathrm{~N}$ & $1.71 \mathrm{~N}$ & High \\
\hline Solitaire 2 & 4.0 & Low & $0.47 \mathrm{~N}$ & $0.75 \mathrm{~N}$ & $0.87 \mathrm{~N}$ & $1.15 \mathrm{~N}$ & $1.31 \mathrm{~N}$ & $1.57 \mathrm{~N}$ & $1.76 \mathrm{~N}$ & High \\
\hline SHELTER ${ }^{\circledR}$ Retriever Lite & 4.5 & Low & $0.03 \mathrm{~N}$ & $0.07 \mathrm{~N}$ & $0.01 \mathrm{~N}$ & $0.09 \mathrm{~N}$ & $0.09 \mathrm{~N}$ & $0.19 \mathrm{~N}$ & $0.17 \mathrm{~N}$ & Low \\
\hline Baby Trevo & 3.0 & Low & $0.66 \mathrm{~N}$ & $0.77 \mathrm{~N}$ & $0.88 \mathrm{~N}$ & $1.12 \mathrm{~N}$ & $1.25 \mathrm{~N}$ & $1.55 \mathrm{~N}$ & $1.71 \mathrm{~N}$ & High \\
\hline Capture LP & 3.0 & Low & $0.34 \mathrm{~N}$ & $1.18 \mathrm{~N}$ & $1.29 \mathrm{~N}$ & $1.44 \mathrm{~N}$ & $1.51 \mathrm{~N}$ & $1.75 \mathrm{~N}$ & $1.86 \mathrm{~N}$ & High \\
\hline
\end{tabular}

MCA, middle cerebral artery; OD, outer diameter; $\mathrm{RF}$, radial force.

\section{RF Testing Procedure}

The test was initially run with no device sample inside the compression station to collect the friction data to be accounted for. Subsequently, each device sample was placed inside the circumferential compression station as shown in Figure 1a, and the device was compressed and relaxed; this represents 1 cycle.

The values measured during the relaxation phase of each cycle represent the outward expansile force or RF. The test parameters used included a total of 3 repeat cycles to average out the RF measurements. One sample of each device, for a given type of retrievable stent or thrombectomy assist device, was tested once, which included 3 automated repetitive cycles (manufacturer default settings of the radial compression station), and the average RF (in newtons) generated by the RF testing software (Blockwise Engineering) was noted in Table 1 and graphically shown in Figure 2.

The initial diameter of the compression station ranged from 4.5 to $7.5 \mathrm{~mm}$ depending on the outer diameter (OD) of the device sample in the expanded configuration. The opening and closing speed of the compression station was set at $0.2 \mathrm{~mm} / \mathrm{s}$ each. The final diameter of the compression station was set at 1.5 $\mathrm{mm}$. The initial and final hold time for the compression station was set at $1 \mathrm{~s}$ each. The sampling period for device testing in the compression station was a total of $50 \mathrm{~s}$ each.

\section{Target Vessel Diameter and RF Groupings}

The total RF generated in vessel diameters (range 2.25-3 mm) seen in proximal LVOs ( M1), and in vessel diameters (range 1.5-2.24 mm) seen in distal LVOs ( M2), was measured.

RF measurements of commercially available carotid stents in long stenosis stimulation studies (which are closest to the RF exerted by a retrievable stent along the length of its deployment) have shown that the RFs are in the range of 0-2 N [15]: Protégé Stent, $1.67 \pm 0.37 \mathrm{~N}$; Acculink Stent, $0.95 \pm 0.12 \mathrm{~N}$; WALLSTENT, $0.80 \pm 0.06 \mathrm{~N}$; and Cristallo Ideale Stent, $0.44 \pm 0.13 \mathrm{~N}$. Single-plane measurements of the RF on intracranial stents have shown similar results of RFs $<2 \mathrm{~N}$ [16]. Therefore, for this study, the actual RF values were collected. In addition, given the existing literature, an RF $\leq 1 \mathrm{~N}$ was grouped as "low" and an RF $>1 \mathrm{~N}$ was grouped as "high" for this analysis.

\section{Laser-Cut Stent Retrievers and Braided Thrombectomy Assist Devices Tested}

Laser-cut stent retrievers that are predominantly used for proximal LVOs (cleared to market in the USA) were studied, including the Trevo ProVue retriever (4.0 mm OD, $25.0 \mathrm{~mm}$ length; Stryker Neurovascular), the Solitaire FR Revascularization Device (4.0 mm OD, 20.0 mm length; Medtronic - Neurovascular), the Solitaire 2 Revascularization Device (4.0 mm OD, $20.0 \mathrm{~mm}$ length; Medtronic - Neurovascular), and the Solitaire Platinum Revascularization Device (6.0 mm OD, $20.0 \mathrm{~mm}$ length; Medtronic - Neurovascular). These devices were compared with a novel braided thrombectomy assist device ( $6.0 \mathrm{~mm}$ distal OD, $45.5 \mathrm{~mm}$ length) named the SHELTER ${ }^{\circledR}$ Retriever (Fig. 1b; Insera Therapeutics, Inc.), which is part of the Insera ${ }^{\mathrm{TM}}$ System and used in conjunction with the CLEAR ${ }^{\mathrm{TM}}$ Aspiration System (the SHELTER ${ }^{\circledR}$ Retriever, CLEAR ${ }^{\mathrm{TM}}$ Aspiration System, and Insera $^{\mathrm{TM}}$ System are not cleared to market in the USA).

Additionally, laser-cut stent retrievers that are predominantly used for distal LVOs (cleared to market in the USA) were studied, including the Trevo XP retriever (3.0 mm OD, $25.0 \mathrm{~mm}$ length; "baby Trevo"; Stryker Neurovascular) and the MindFrame Capture LP Revascularization Device (3.0 mm OD, $15.0 \mathrm{~mm}$ 
Fig. 2. a Radial force progression in stent retrievers that are predominantly used for proximal large vessel occlusions. b Radial force progression in stent retrievers that are predominantly used for distal large vessel occlusions.

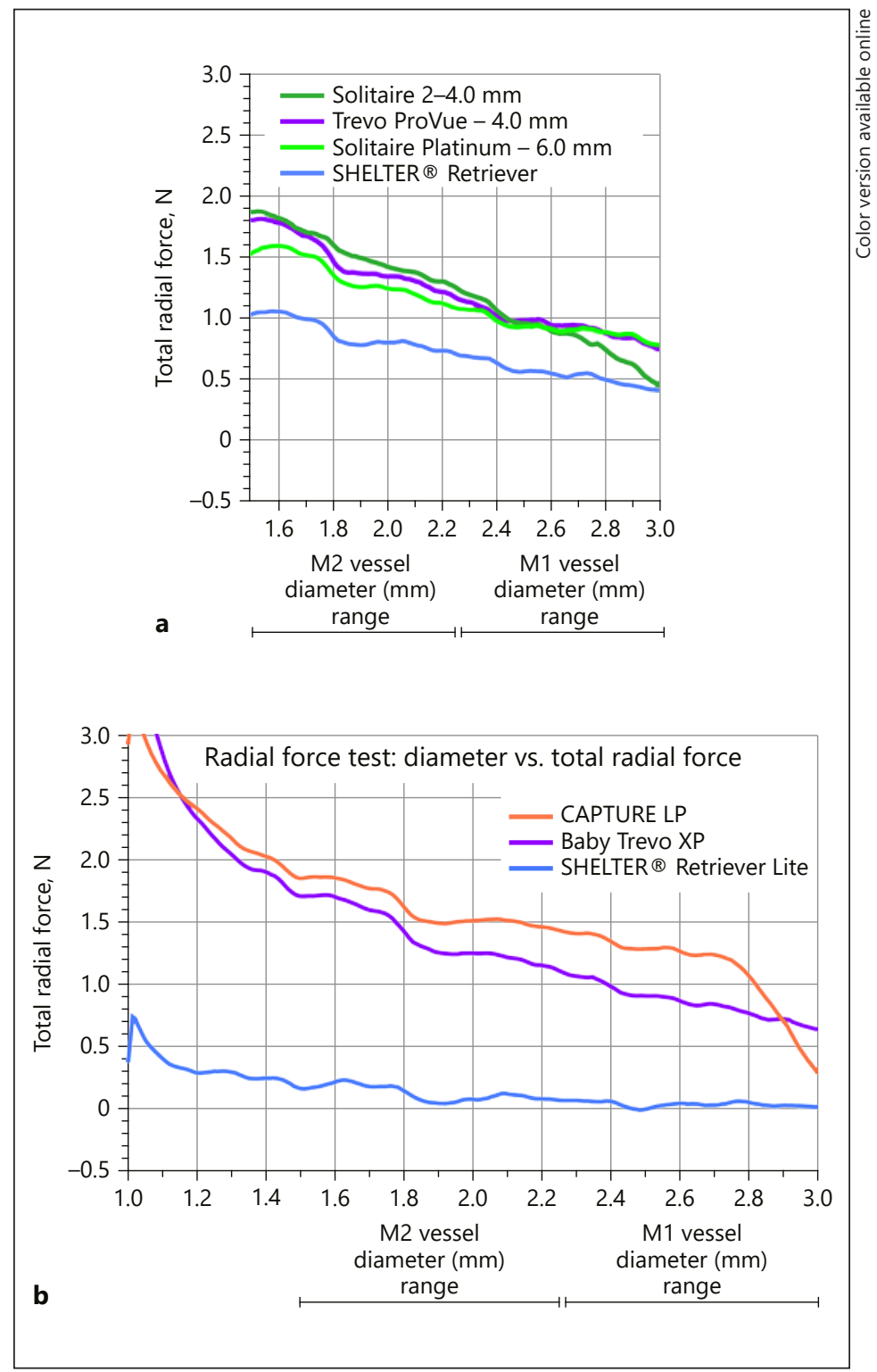

length; Medtronic - Neurovascular). These devices were compared with a novel braided thrombectomy assist device (4.5 mm distal OD, $43 \mathrm{~mm}$ length) named the SHELTER ${ }^{\circledR}$ Retriever Lite (Insera Therapeutics, Inc.), which is part of the Insera ${ }^{\mathrm{TM}}$ System and used in conjunction with the CLEAR ${ }^{\mathrm{TM}}$ Aspiration System (not cleared to market in the USA).

\section{Results}

The RF test results for vessel diameters seen in proximal LVOs $(\sim \mathrm{M} 1)$ (range 2.25-3 $\mathrm{mm}$ ), as well as those for vessel diameters seen in distal LVOs ( M2) (range 1.5-2.24 mm), are shown in Table 1 and Figure 2. The total RFs of all laser-cut stent retrievers were all higher in the simulated M2 vessels ( $>1 \mathrm{~N})$ than in the simulated M1 vessels $(\leq 1 \mathrm{~N})$, whereas the total RFs of the braided thrombectomy assist devices were uniformly low in both the simulated M1 and the simulated M2 vessels (Table 1; Fig. 2). 
The above RF testing was performed with the devices placed within a circumferential compression station (Fig. 1a). There was no push, pull, or withdrawal of devices during RF testing, as the circumferential compression technique used does not permit dynamic manipulation of devices.

\section{Discussion}

The use of endovascular stroke thrombectomy devices has revolutionized the management, and improved the outcomes, of acute ischemic stroke involving LVOs. The purpose of this study was to determine the RF of a novel braided thrombectomy assist device that is used in conjunction with an aspiration system, compared to current commercially available stent retrievers, in an in vitro experiment. Using a tensile testing machine (TTR2 Machine Base), the total RFs of all laser-cut stent retrievers were found to be higher in the simulated M2 vessels $(>1 \mathrm{~N})$ than in the simulated M1 vessels $(<1 \mathrm{~N})$, whereas the total RFs of the braided thrombectomy assist devices were uniformly low in both the simulated M1 $(<1 \mathrm{~N})$ and the simulated M2 $(>1 \mathrm{~N})$ vessels. It has been noted throughout all stent devices that the RF gradually drops as the vessel diameter increases.

Stent retrievers are self-expanding stents that entrap a thrombus by expanding along its length, and sometimes they push the thrombus against the vessel wall. The stents are then withdrawn in their unfolded state, maintaining the RF against the vessel wall until reaching the delivery catheter. The exponential growth in stent retriever use has led to an increase in the recognition of their inherent complications and limitations in clinical practice. Several publications, including MR CLEAN, SWIFT, HERMES, REVASCAT, and TREVO 2, among others, have reported complications associated with their use [5]. Gascou et al. [17] estimated that $>10 \%$ of thrombectomy procedures are associated with perioperative complications, includingarterial perforation(0.9-4.9\%), intracerebralhemorrhage(3.6-9.3\%), subarachnoid hemorrhage (0.6-4.9\%), arterial dissection (0.6-3.9\%), distal embolization (1-8.6\%), and vasospasm $(3.9-23 \%)[5,18]$.

Various theories have been postulated regarding the emergence of these complications. One of the hypothesized mechanisms is endothelial injury during stent expansion and clot retrieval [19-22]. The stent expansion pressure measured by RF is the outward expansile force of the stent against the vessel wall. Although a constantly high RF was associated with higher rates of clot removal [23], it was also associated with endothelial vessel wall injury (VWI) [20,24]. Therefore, minimizing the RF in stent retriever devices may reduce the incidence of VWI complications while still maintaining optimal clot retrieval rates. Endothelial injury may contribute to the observed clinical discrepancies even when successful recanalization is achieved [24]. Additionally, mechanical disruption of vessel wall integrity, and the following inflammatory responses initiated at the molecular level, may lead to consequential neuronal injury [19]. In a rabbit model of carotid artery stent retriever thrombectomy using the Solitaire FR and Trevo ProVue stent retrievers, Arai et al. [25] demonstrated histological evidence of disruption and thickening of the intimal layer extending into the media. In fact, certain characteristic patterns of endothelial injury have been reported following the use of stent retrievers. Both complete circumferential and linear VWIs were observed on an in vitro live-cell platform [19].

Several radiological studies using HDx 3.0-T MRI scanners have depicted VWI and bloodbrain barrier disruption in patients following endovascular stent retriever procedures [26, 27]. Contrasted T1-weighted imaging demonstrated vessel wall enhancement in segments where the stent retrievers were deployed. Additionally, enhancement was more prominent in patients who underwent thrombectomy than in those who received IV tPA alone, thereby 
excluding the possibility that the embolus is causing endothelial damage [28]. The various patterns of VWI detected in both histological and radiological studies mandates continuous modifications and innovations in endovascular devices and techniques. We believe that the novel braided thrombectomy assist devices with a lower RF compared to laser-cut stent retrievers may prevent, or at least diminish, the incidence of VWIs observed in these studies by reducing the RF on M1 and M2 vessels. In vitro flow model tests with clots to assess their efficacy, as well as in vivo animal studies to assess their safety, are needed to delineate the benefits and limitations of aspiration systems used alone or in combination with a braided thrombectomy assist device design and to expand our understanding of their role in the management of acute strokes in humans.

The strengths of this study include the novel testing method used for assessing the RF of retrievable stents and thrombectomy assist devices. Traditionally, the RF of a stent is measured by compressing the stent in a single axial plane $[16,23]$, whereas in this study, the RFs of all stents were measured by circumferentially compressing stents in multiple planes for a more accurate measurement. Although stents outside the neurovasculature, such as coronary stents, have been studied using a circumferential compression technique, this is the first study to document the RF of stroke thrombectomy devices using this method. The authors anticipate for the future that the RF, in addition to the OD of the retrievable stent, should jointly serve as guiding metrics for appropriately sizing retrievable stents to the target vessel with the goal of minimizing VWI.

This study is limited by several factors. Primarily, mechanical bench testing lacks the ability to foresee complications that may occur during clot retrieval from organic blood vessels. Additionally, total RF measurement using a radial compression station mounted on a tensile testing machine does not mimic the biological endothelial responses to a braided thrombectomy assist device. Nonetheless, the utilization of mechanical bench testing has ensured identical conditions for all RF measurements with all thrombectomy assist devices.

\section{Conclusions}

Endovascular thrombectomy devices are increasing in popularity due to their ease of use and effectiveness in the acute treatment of ischemic stroke due to LVO. However, this widespread increase in use has alerted clinicians to their perioperative complications. VWI is linked to the development of clinical complications seen following the use of stent retrievers. The sizing of stent retrievers' OD should not be the only factor considered while targeting vessels for thrombectomy, as the devices' total RF is also likely impactful. In this study, choosing a stent retriever with a lower OD did not translate into a lower RF. Novel braided thrombectomy assist devices for use in conjunction with aspiration systems have a lower RF than existing laser-cut stent retrievers in simulated M1 and M2 vessel diameters. Further in vivo studies are needed to assess the impact of aspiration systems used alone or in combination with braided thrombectomy assist devices with lower RFs on minimizing VWIs compared to higher-RF laser-cut stent retrievers.

\section{Statement of Ethics}

As this paper did not involve any animal models or human subjects, and purely involved mechanical bench testing, ethics approval was not required. 


\section{Disclosure Statement}

Vikram Janardhan and Vallabh Janardhan are the majority shareholders in Insera Therapeutics, Inc. The remaining authors report no conflict of interest concerning the materials or methods used in this study or the findings specified in this paper.

\section{Funding Sources}

This study was funded in part by a research grant (NSF Award: 1819491; PI: Vallabh Janardhan, MD) from the National Science Foundation (NSF).

\section{References}

1 Mozaffarian D, Benjamin EJ, Go AS, Arnett DK, Blaha MJ, Cushman M, et al.; Writing Group Members; American Heart Association Statistics Committee; Stroke Statistics Subcommittee. Heart Disease and Stroke Statistics-2016 Update: A Report from the American Heart Association. Circulation. 2016 Jan;133(4):e38-360.

2 Adams HP Jr, del Zoppo G, Alberts MJ, Bhatt DL, Brass L, Furlan A, et al.; American Heart Association/American Stroke Association Stroke Council; American Heart Association/American Stroke Association Clinical Cardiology Council; American Heart Association/American Stroke Association Cardiovascular Radiology and Intervention Council; Atherosclerotic Peripheral Vascular Disease Working Group; Quality of Care Outcomes in Research Interdisciplinary Working Group. Guidelines for the early management of adults with ischemic stroke: a guideline from the American Heart Association/American Stroke Association Stroke Council, Clinical Cardiology Council, Cardiovascular Radiology and Intervention Council, and the Atherosclerotic Peripheral Vascular Disease and Quality of Care Outcomes in Research Interdisciplinary Working Groups: The American Academy of Neurology affirms the value of this guideline as an educational tool for neurologists. Circulation. 2007 May;115(20):e478534.

3 Padma S, Majaz M. Intra-arterial versus intra-venous thrombolysis within and after the first 3 hours of stroke onset. Arch Med Sci. 2010 Jun;6(3):303-15.

4 Nogueira RG, Lutsep HL, Gupta R, Jovin TG, Albers GW, Walker GA, et al. Trevo versus Merci retrievers for thrombectomy revascularisation of large vessel occlusions in acute ischaemic stroke (TREVO 2): a randomised trial. Lancet. 2012 Oct;380(9849):1231-40.

5 Goyal M, Menon BK, van Zwam WH, Dippel DW, Mitchell PJ, Demchuk AM, et al.; HERMES collaborators. Endovascular thrombectomy after large-vessel ischaemic stroke: a meta-analysis of individual patient data from five randomised trials. Lancet. 2016 Apr;387(10029):1723-31.

6 Nogueira RG, Jadhav AP, Haussen DC, Bonafe A, Budzik RF, Bhuva P, et al.; DAWN Trial Investigators. Thrombectomy 6 to 24 Hours after Stroke with a Mismatch between Deficit and Infarct. N Engl J Med. 2018 Jan;378(1): $11-21$.

7 Albers GW, Marks MP, Kemp S, Christensen S, Tsai JP, Ortega-Gutierrez S, et al.; DEFUSE 3 Investigators. Thrombectomy for Stroke at 6 to 16 Hours with Selection by Perfusion Imaging. N Engl J Med. 2018 Feb;378(8):708-18.

8 Spiotta AM, Chaudry MI, Hui FK, Turner RD, Kellogg RT, Turk AS. Evolution of thrombectomy approaches and devices for acute stroke: a technical review. J Neurointerv Surg. 2015 Jan;7(1):2-7.

9 Lapergue B, Blanc R, Gory B, Labreuche J, Duhamel A, Marnat G, et al.; ASTER Trial Investigators. Effect of endovascular contact aspiration vs stent retriever on revascularization in patients with acute ischemic stroke and large vessel occlusion: the ASTER randomized clinical trial. JAMA. 2017 Aug;318(5):443-52.

10 Turk AS 3rd, Siddiqui A, Fifi JT, De Leacy RA, Fiorella DJ, Gu E, et al. Aspiration thrombectomy versus stent retriever thrombectomy as first-line approach for large vessel occlusion (COMPASS): a multicentre, randomised, open label, blinded outcome, non-inferiority trial. Lancet. 2019 Mar;393(10175):998-1008.

11 Fargen KM, Arthur AS, Spiotta AM, Lena J, Chaudry I, Turner RD, et al. A survey of neurointerventionalists on thrombectomy practices for emergent large vessel occlusions. J Neurointerv Surg. 2017 Feb;9(2):142-6.

12 Mehta T, Male S, Quinn C, Kallmes DF, Siddiqui AH, Turk A, et al. Institutional and provider variations for mechanical thrombectomy in the treatment of acute ischemic stroke: a survey analysis. J Neurointerv Surg. 2019 [Epub ahead of print].

13 Nogueira RG, Frei D, Kirmani JF, Zaidat O, Lopes D, Turk AS 3rd, et al.; Penumbra Separator 3D Investigators. Safety and efficacy of a 3-dimensional stent retriever with aspiration-based thrombectomy vs aspiration-based thrombectomy alone in acute ischemic stroke intervention: a randomized clinical trial. JAMA Neurol. $2018 \mathrm{Mar}$; 75(3):304-11.

14 Ding D. Endovascular mechanical thrombectomy for acute ischemic stroke: a new standard of care. J Stroke. 2015 May;17(2):123-6.

15 Voûte MT, Hendriks JM, van Laanen JH, Pattynama PM, Muhs BE, Poldermans D, et al. Radial force measurements in carotid stents: influence of stent design and length of the lesion. J Vasc Interv Radiol. 2011 May;22(5):661-6. 
16 Krischek O, Miloslavski E, Fischer S, Shrivastava S, Henkes H. A comparison of functional and physical properties of self-expanding intracranial stents [Neuroform3, Wingspan, Solitaire, Leo+, Enterprise]. Minim Invasive Neurosurg. 2011 Feb;54(1):21-8.

17 Gascou G, Lobotesis K, Machi P, Maldonado I, Vendrell JF, Riquelme C, et al. Stent retrievers in acute ischemic stroke: complications and failures during the perioperative period. AJNR Am J Neuroradiol. 2014 Apr;35(4): 734-40.

18 Balami JS, White PM, McMeekin PJ, Ford GA, Buchan AM. Complications of endovascular treatment for acute ischemic stroke: prevention and management. Int J Stroke. 2018 Jun;13(4):348-61.

19 Teng D, Pannell JS, Rennert RC, Li J, Li YS, Wong VW, et al. Endothelial trauma from mechanical thrombectomy in acute stroke: in vitro live-cell platform with animal validation. Stroke. 2015 Apr;46(4):1099-106.

20 Peschillo S, Tomasello A, Diana F, Hernandez D, Toccaceli G, Rosal-Fontana M, et al. Comparison of Subacute Vascular Damage Caused by ADAPT versus Stent Retriever Devices after Thrombectomy in Acute Ischemic Stroke: Histological and Ultrastructural Study in an Animal Model. Intervent Neurol. 2018 Oct;7(6):501-12.

21 Perren F, Kargiotis O, Pignat JM, Pereira VM. Hemodynamic Changes May Indicate Vessel Wall Injury after Stent Retrieval Thrombectomy for Acute Stroke. J Neuroimaging. 2018 Jul;28(4):412-5.

22 Saver JL, Jahan R, Levy EI, Jovin TG, Baxter B, Nogueira RG, et al.; SWIFT Trialists. Solitaire flow restoration device versus the Merci Retriever in patients with acute ischaemic stroke (SWIFT): a randomised, parallelgroup, non-inferiority trial. Lancet. 2012 Oct;380(9849):1241-9.

23 Machi P, Jourdan F, Ambard D, Reynaud C, Lobotesis K, Sanchez M, et al. Experimental evaluation of stent retrievers' mechanical properties and effectiveness. J Neurointerv Surg. 2017 Mar; 9(3):257-63.

24 Chon CH, Qin Z, Lam AKN, Kwok JCK, Yuen MM, Lam DC. In-vitro testing of RF-enabled low force mechanical thrombectomy for ischemic stroke. Conf Proc IEEE Eng Med Biol Soc. 2015 Aug;2015:1349-52.

25 Arai D, Ishii A, Chihara H, Ikeda H, Miyamoto S. Histological examination of vascular damage caused by stent retriever thrombectomy devices. J Neurointerv Surg. 2016 Oct;8(10):992-5.

26 Abraham P, Scott Pannell J, Santiago-Dieppa DR, Cheung V, Steinberg J, Wali A, et al. Vessel wall signal enhancement on 3-T MRI in acute stroke patients after stent retriever thrombectomy. Neurosurg Focus. 2017 Apr;42(4):E20.

27 Power S, Matouk C, Casaubon LK, Silver FL, Krings T, Mikulis DJ, et al. Vessel wall magnetic resonance imaging in acute ischemic stroke: effects of embolism and mechanical thrombectomy on the arterial wall. Stroke. 2014 Aug;45(8):2330-4.

28 Kidwell CS, Jahan R, Gornbein J, Alger JR, Nenov V, Ajani Z, et al.; MR RESCUE Investigators. A trial of imaging selection and endovascular treatment for ischemic stroke. N Engl J Med. 2013 Mar;368(10):914-23. 